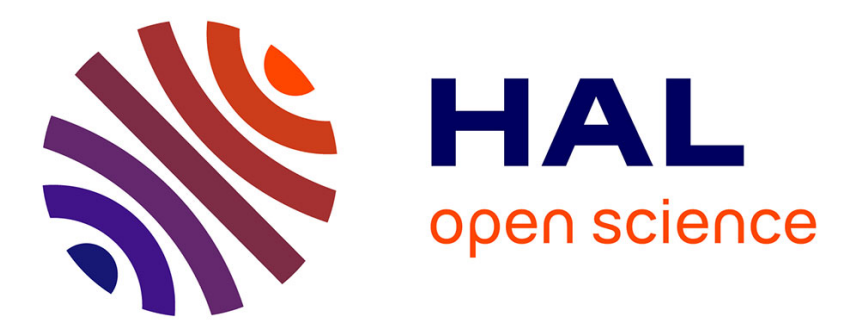

\title{
Trends and random walks in macroeconomic time series: A reappraisal
}

\author{
Amélie Charles, Olivier Darné
}

\section{To cite this version:}

Amélie Charles, Olivier Darné. Trends and random walks in macroeconomic time series: A reappraisal. Journal of Macroeconomics, 2012, 34 (1), pp.167-180. 10.1016/j.jmacro.2011.10.001 . hal-00956937

\section{HAL Id: hal-00956937 https://hal.science/hal-00956937}

Submitted on 29 Apr 2015

HAL is a multi-disciplinary open access archive for the deposit and dissemination of scientific research documents, whether they are published or not. The documents may come from teaching and research institutions in France or abroad, or from public or private research centers.
L'archive ouverte pluridisciplinaire HAL, est destinée au dépôt et à la diffusion de documents scientifiques de niveau recherche, publiés ou non, émanant des établissements d'enseignement et de recherche français ou étrangers, des laboratoires publics ou privés. 


\title{
Trends and random walks in macroeconomic time series: A reappraisal
}

\author{
Amélie CHARLES* and Olivier DARNÉ ${ }^{\dagger}$
}

\begin{abstract}
In this paper we re-analyze the nature of the trend (deterministic or stochastic) in the Nelson-Plosser macroeconomic data set from an alternative method relative to the previous studies. We underline the effects of large, but infrequent shocks due to major economic or financial events on U.S. macroeconomic time series, such as the Great Depression, World War II and recessions, using outlier methodology. We apply an ADF test corrected for detected outliers based on intervention models and calculate the specific critical values of the unit root tests for each series. The results point out the rejection of the unit root null hypothesis for five of the fourteen Nelson-Plosser macroeconomic time series, namely real GNP, real per capita GNP, industrial production, employment and unemployment.
\end{abstract}

Keywords: Macroeconomic time series; unit root; outliers.

JEL Classification: C12; C22

*Audencia Nantes, School of Management, 8 route de la Jonelière, 44312 Nantes Cedex 3. Email: acharles@audencia.com.

${ }^{\dagger}$ Corresponding author: LEMNA, University of Nantes, IEMN-IAE, Chemin de la Censive du Tertre, BP 52231, 44322 Nantes, France. Email: olivier.darne@univ-nantes.fr. 


\section{Introduction}

Since the influential paper of Nelson and Plosser (1982), much attention has been devoted to examining whether macroeconomic time series are trend or difference stationary. Indeed, different models of the trend can imply different conclusions concerning the validity of economic theories and can imply different policy implications for macroeconomic models. If the series is trend-stationary, and is thus characterized by stationary movements around a deterministic trend, a shock has only a temporary effect and the series reverts to its steady trend after the shock. In contrast, if the series is difference stationary (or has a unit root), and is therefore characterized by a random walk (possibly with a drift), a shock has a persistent effect. As a result, the series does not return to its former path following a random disturbance, and its level shifts permanently.

Applying the unit root tests developed by Dickey and Fuller (1979) on a wide variety of U.S. macroeconomic time series, Nelson and Plosser (1982) found that the null hypothesis of a unit root could be rejected for only one out of the fourteen macroeconomic time series in their data set, i.e. the unemployment rate. Their finding had a profound impact on the way economic series have been viewed and treated (Banerjee and Urga, 2005); in particular, if the series were indeed integrated, random shocks would have a permanent effect on the economy.

However, several authors pointed out that the tests employed by Nelson and Plosser have a drawback related to the presence of breaks, i.e. that structural breaks can be biased towards erroneous non-rejection of the unit root hypothesis (e.g., Perron, 1989; Rappoport and Reichlin, 1989; Montañés and Reyes, 1998; Leybourne et al., 1998; Sen, 2008). ${ }^{1}$ A number of tests have been developed to take into account a structural change, where the date of the break is $a$ priori unknown, namely the breakpoint is determined endogenously from the data. $^{2}$ In this way, many researchers revisited the Nelson-Plosser empirical results using unit root tests with structural breaks, allowing for one (e.g., Zivot and Andrews, 1992; Li, 1995; Perron, 1997; Sen, 2004; Montañés et al., 2005)

\footnotetext{
${ }^{1}$ More precisely, Perron (1989) and Rappoport and Reichlin (1989) demonstrated that unit root tests fail to reject the unit root null hypothesis when there is a break under the trendstationary alternative. Further, Nunes et al. (1997), Montañés and Reyes (1998), Leybourne et al. (1998), Lee and Strazicich (2001) and Sen (2008) found that unit root tests spuriously reject the unit root null when there is a break under the null hypothesis.

${ }^{2}$ See the special 1992 issue of Journal of Business an Economic Statistics 10(3).
} 
or two (Lumsdaine and Papell, 1997; Lee and Strazicich, 2003; Papell and Prodan, 2007) structural changes. ${ }^{3}$ Most of these studies tended to contradict the findings of Nelson-Plosser, i.e. there was less evidence in favor of the unit root hypothesis. Nevertheless, the unit root tests with structural breaks impose a number of structural breaks without prior knowledge of their number, which may strongly bias the results of the tests and the estimation of the dates of the structural changes (Kim et al., 2000). In addition, these tests generally propose three models according to the type of breaks (changes in the intercept of the trend function, changes in the slope of the trend function, or changes in the intercept and the slope of the trend function) but do not select them. This can give different results depending on the model chosen (Lee and Strazicich, 2001; Sen, 2003; Montañés et al., 2005).

It has also been shown that unit root tests can be disturbed by the presence of outliers (Franses and Haldrup, 1994; Lucas, 1995; Shin et al., 1996; Yin and Maddala, 1997; Cavaliere and Georgiev, 2009), especially additive outliers, which affect only a single observation at some points in time series and not its future values. Indeed, the presence of additive outliers induces in the errors a negative moving-average component, which causes the unit root tests to exhibit substantial size distortions towards rejecting the null hypothesis too often (Vogelsang, 1999; Rodriguez, 2004). ${ }^{4}$

For these reasons, we re-examine the Nelson-Plosser data set from a new perspective. First, we consider that the major economic events represent major shocks that occur infrequently (low-frequency shocks), but that their occurrence is randomly determined. This approach results from the fact that there are numerous examples of random, heterogeneous, and infrequent events that have a dramatic impact on the economy, especially for long-term economic series (e.g., oil crises, wars, financial slumps, changes of political regime, and natural catastrophes). We therefore seek the presence of these shocks, which can have a permanent or temporary effect, in the form of outliers, providing a certain amount of information about the nature and magnitude of the economic shocks

\footnotetext{
${ }^{3}$ Nunes et al. (1997) provide evidence that assuming no break under the null in endogenous break unit root test leads to significant rejection of the unit root null when the data generating process is a unit root with break (see Perron, 2006). This the case for some of the tests cited. Lee and Strazicich (2003) suggested an endogenous break LM unit root test, which permits a break under the null as well as under the alternative.

${ }^{4}$ Vogelsang (1999), Perron and Rodriguez (2003b) and Haldrup and Sansó (2008) suggested procedures for detecting multiple additive outliers in nonstationary time series.
} 
in the U.S. Next, we seek the deterministic or stochastic nature of the trend in the Nelson-Plosser macroeconomic time series by estimating intervention models based upon the outlier analysis and performing Dickey-Fuller unit root tests on the intervention models as in Balke and Fomby (1991), Bradley and Jansen (1995), and Rodriguez (2004). In this case, the random walk with drift implies permanent shocks that are assumed to be randomly generated every observation period (high-frequency shocks). ${ }^{5}$ This approach allows to distinguishing between frequent small shocks due to period-by-period permanent innovations (as in the case of a stochastic trend) and infrequent large shocks due to significant economic and financial events. Our results reject a unit root for five of the fourteen series in the Nelson-Plosser data set, namely real GNP, real per capita GNP industrial production, employment and unemployment. These results are confirmed by applying robust unit root tests proposed by Cavaliere and Georgiev (2009).

The paper is structured as follows. In Section 2, the methodology for detecting outliers is described. The detected outliers that can be associated with major economic or financial events are discussed in Section 3. Section 4 presents the results of the Dickey-Fuller tests on the intervention models, interprets these results, and provides a comparison with a robust approach. Section 5 concludes the paper.

\section{Outlier Methodology}

The search for outliers is based on an unobserved components model with two such components: a regular one and an outlier one. The latter reflects extraordinary, infrequently occurring events or shocks that have important effects on the macroeconomic time series. The model is given by

$$
z_{t}=y_{t}+f(t)
$$

\footnotetext{
${ }^{5}$ Another interesting approach is proposed by Lucas (1995a, b), Hoek et al. (1995), Xiao and Lima (2005), Lima and Filho (2008) and Cavaliere and Georgiev (2009) with robust estimations. However, in most cases, researchers need to know the dates of the outliers. This is our case because among other reasons, dates of the outliers allow us to identify which phenomena are related to these dates. Darné and Diebolt (2004) suggest a two-step procedure, i.e. (i) outlier detection, (ii) unit root tests on outlier corrected data, but they only investigated size performance, not power performance.
} 
where

$$
y_{t}=\frac{\theta(L)}{\alpha(L) \phi(L)} a_{t} \quad a_{t} \sim N\left(0, \sigma_{a}^{2}\right)
$$

$y_{t}$ is an $\operatorname{ARIMA}(p, d, q)$ process and $f(t)$ contains exogenous disturbances or outliers. Following Chen and Liu (1993), we will consider four types of outliers: additive outlier (AO), innovation outlier (IO), level shift (LS), and temporary change (TC). The models for different $f(t)$ are as follows

$$
\begin{aligned}
\text { AO: } & f(t)_{A O}=\omega_{A O} I_{t}(\tau) \\
\text { LS: } & f(t)_{L S}=[1 /(1-L)] \omega_{L S} I_{t}(\tau) \\
\text { IO: } & f(t)_{I O}=[\theta(L) / \alpha(L) \phi(L)] \omega_{I O} I_{t}(\tau) \\
\text { TC: } & f(t)_{T C}=[1 /(1-\delta L)] \omega_{T C} I_{t}(\tau)
\end{aligned}
$$

where $\omega_{i}, i=\mathrm{AO}, \mathrm{IO}, \mathrm{LS}, \mathrm{TC}$, denotes the magnitudes of the outlier, and $I_{t}(\tau)$ is an indicator function with the value of 1 at time $t=\tau$ and 0 otherwise, with $\tau$ the date of outlier occurring.

These outliers affect the observations differently: AO causes an immediate and one-shot effect on the observed series; LS produces an abrupt and permanent step change in the series (permanent shock); TC produces an initial effect, and this effect dies out gradually with time, where the parameter $\delta$ is designed to model the pace of the dynamic dampening effect $(0<\delta<1)$; the effect of IO is more intricate than the effects of the others types of outliers. ${ }^{6}$ IO produces a temporary effect for a stationary series, but produces a permanent level shift for a nonstationary series (see Chen and Liu, 1993).

It is considered that AOs and IOs are outliers related to an exogenous and endogenous change in the series, respectively, whereas TCs and LSs are are associated with structural changes. TCs represent ephemeral shifts in a series, whereas LSs are more the reflection of permanent shocks. However, IOs have a relatively persistent effect on the level of the series. Note that level shifts and (nonstationary) innovative outliers detected in levels of the time series correspond to additive or innovative outliers in first-difference, i.e. in growth rates (Balke and Fomby, 1991; Maddala and Kim, 2000).

Methods are well-developed in the field of outlier detection based on intervention analysis as originally proposed by Box and Tiao (1975). This approach

\footnotetext{
${ }^{6}$ Indeed, except for the case of IO, the effects of outliers on the observed series are independent of the model. Chen and Liu (1993) set $\delta=0.7$.
} 
requires iterations between stages of outlier detection and estimation of an intervention model. Procedures considered by Chang et al. (1988) and Tsay (1988) are quite effective in detecting the locations and estimating the effects of large isolated outliers. However, these procedures display some drawbacks: (i) the presence of outliers may result in an inappropriate model; (ii) even if the model is appropriately specified, outliers in a time series may still produce bias in parameter estimates and hence may affect the efficiency of outlier detection; and (iii) some outliers can not be identified due to a masking effect. To overcome these problems, Chen and Liu (1993) proposed an iterative outlier detection and adjustment procedure to obtain joint estimates of model parameters and outlier effects. In their procedure the types and effects of outliers are based on less contaminated estimates of model parameters, the outlier effects being estimated simultaneously using multiple regression, and the model parameters and the outlier effects $\left(\omega_{i}\right)$ are estimated jointly. ${ }^{7}$ Here we use the Chen-Liu method modified by Gómez and Maravall (1997). ${ }^{8}$ This procedure is described below.

An ARIMA model is fitted to $y_{t}$ in (2) and the residuals are obtained

$$
\hat{a}_{t}=\pi(B) z_{t}
$$

where $\pi(B)=\alpha(B) \phi(B) / \theta(B)=1-\pi_{1} B-\pi_{2} B^{2}-\ldots$

For the four types of outliers in (1), the equation (4) becomes

$$
\begin{aligned}
\mathrm{AO}: & \hat{a}_{t}=a_{t}+\omega_{A O} \pi(B) I_{t}(\tau) \\
\mathrm{IO}: & \hat{a}_{t}=a_{t}+\omega_{I O} I_{t}(\tau) \\
\mathrm{LS}: & \hat{a}_{t}=a_{t}+\omega_{L S}[\pi(B) /(1-B)] I_{t}(\tau) \\
\mathrm{TC}: & \hat{a}_{t}=a_{t}+\omega_{T C}[\pi(B) /(1-\delta B)] I_{t}(\tau)
\end{aligned}
$$

These expressions can be viewed as a regression model for $\hat{a}_{t}$, i.e.,

$$
\hat{a}_{t}=\omega_{i} x_{i, t}+a_{t} \quad i=\mathrm{AO}, \mathrm{IO}, \mathrm{LS}, \mathrm{TC},
$$

\footnotetext{
${ }^{7}$ From a simulation study, Chen and Liu (1993) show that their procedure performs well in terms of detecting outliers and obtaining unbiased parameter estimates.

${ }^{8}$ Gómez and Maravall (1997) implemented this method in the computer program TRAMO. Franses and Haldrup (1994), Tolvi (2001) and Darné and Diebolt (2004) also used this method to detect and correct outliers in macroeconomic series whereas Balke and Fomby $(1991,1994)$ and Bradley and Jansen (1995) applied that of Tsay (1988).
} 
with $x_{i, t}=0$ for all $i$ and $t<\tau, x_{i, t}=1$ for all $i$ and $t=\tau$, and for $t>\tau$ and $k \geq 1, x_{A O, t+k}=-\pi_{k}(\mathrm{AO}), x_{I O, t+k}=0(\mathrm{IO}), x_{L S, t+k}=1-\sum_{j=1}^{k} \pi_{j}$ (LS) and $x_{T C, t+k}=\delta^{k}-\sum_{j=1}^{k-1} \delta^{k-j} \pi_{j}-\pi_{k}$ (TC).

The detection of the outliers is based on likelihood ratio [LR] statistics, given by

$$
\begin{array}{rlrl}
\text { AO: } & & \hat{\tau}_{A O}(\tau)=\left[\hat{\omega}_{A O}(\tau) / \hat{\sigma}_{a}\right] /\left(\sum_{t=\tau}^{n} x_{A O, t}^{2}\right)^{1 / 2} \\
\text { IO: } & \hat{\tau}_{I O}(\tau)=\hat{\omega}_{I O}(\tau) / \hat{\sigma}_{a} \\
\text { LS: } & \hat{\tau}_{L S}(\tau)=\left[\hat{\omega}_{L S}(\tau) / \hat{\sigma}_{a}\right] /\left(\sum_{t=\tau}^{n} x_{L S, t}^{2}\right)^{1 / 2} \\
\text { TC: } & \hat{\tau}_{T C}(\tau)=\left[\hat{\omega}_{T C}(\tau) / \hat{\sigma}_{a}\right] /\left(\sum_{t=\tau}^{n} x_{T C, t}^{2}\right)^{1 / 2} \\
\text { with } & \hat{\omega}_{i}(\tau)=\sum_{t=\tau}^{n} \hat{a}_{t} x_{i, t} / \sum_{t=\tau}^{n} x_{i, t}^{2} \\
\text { and } & \hat{\omega}_{I O}(\tau)=\hat{a}_{\tau}
\end{array}
$$

where $\hat{\omega}_{i}(\tau)(i=\mathrm{AO}, \mathrm{IO}, \mathrm{LS}, \mathrm{TC})$ denotes the estimation of the outlier impact at time $t=\tau$, and $\hat{\sigma}_{a}$ is an estimate of the variance of the residual process (Chang et al., 1988).

Outliers are identified by running a sequential detection procedure, consisting of outer and inner iterations. In the outer iteration, assuming that there are no outliers, an initial $\operatorname{ARIMA}(p, d, q)$ model is estimated and the residuals are obtained $\left(\hat{a}_{t}\right)$. The results from the outer iteration are then used in the inner iteration to identify outliers. The LR test statistics for the four types of outliers are calculated for each observation. The largest absolute value of these test statistics

$$
\hat{\tau}_{\max }=\max \left|\hat{\tau}_{i}(\tau)\right| \quad i=\mathrm{AO}, \mathrm{IO}, \mathrm{LS}, \mathrm{TC} \text { and } \tau=1, \ldots, T
$$

is compared with a critical value, and if the test statistic is larger, an outlier is found at time $t=\tau_{1}$ and its type is selected $\left(i^{*}\right)$. When an outlier is detected, the effect of the outlier is removed from the data as follows: the observation $z_{t}$ is adjusted at time $t=\tau_{1}$ to obtain the corrected $y_{t}$ via (1) using the estimated magnitude $\hat{\omega}_{i^{*}}$ and the appropriate structure of outlier $f(t)_{i^{*}}$ as in (3), i.e.

$$
y_{t}=z_{t}-f(t)_{i^{*}}
$$


We also compare the second largest absolute value of the LR statistics for the four types of outliers to the critical value, i.e. $\hat{\tau}_{\max }=\max \left|\hat{\tau}_{i}(\tau)\right|$ with $\tau \neq \tau_{1}$, and so on. This process is repeated until no more outliers can be found. Next, we return to the outer iteration in which another $\operatorname{ARIMA}(p, d, q)$ model is re-estimated from the outlier-corrected data, and start the inner iteration again. This procedure is repeated until no outlier is found. Finally, a multiple regression is performed on the various outliers detected to identify (possible) spurious outliers. ${ }^{9}$

\section{Infrequent Large Shocks and Nelson-Plosser data set}

We study the 14 annual U.S. macroeconomic data sets used by Nelson and Plosser (1982): Real GNP, nominal GNP, real per capita GNP, industrial production, employment, unemployment, GNP deflator, consumer price, nominal wages, real wages, money stock, velocity, interest rate, and stock price. The data consists of annual observations which begin between 1860 and 1909 . In this paper we consider an extension of the Nelson-Plosser data set to include the observations up to $1988 .{ }^{10}$ This extension was compiled by Schotman and van Dijk (1991). The logarithmic transformation is applied to the data, except for the interest rate.

\subsection{Descriptive Statistics}

Tables 1 and 2 display the ARIMA specifications for all the variables. As suggested by Andreou and Spanos (2003), we also report some descriptive statistics from ARIMA models to assess statistical adequacy ${ }^{11}$ : normality, non-

\footnotetext{
${ }^{9}$ See Tolvi (2001) for a detailed discussion on the outlier detection procedure. The initial $\operatorname{ARIMA}(p, d, q)$ model is based on specification tests and information criteria. Further, estimating the initial $\operatorname{ARIMA}(p, d, q)$ model can lead us to misidentify level shifts as innovational outliers, or not detect them. Therefore, as suggested by Balke and Fomby (1991) and Balke (1993), an outlier search has been conducted from an $\operatorname{ARIMA}(p, 0, q)$ to better determine whether the outliers can be considered permanent or not. Finally, the outlier detection has been examined on the series in growth rates, and we found the same type of outliers as for the series in levels.

${ }^{10}$ We have obtained similar results when using the same span of data as in Nelson and Plosser (1982).

${ }^{11}$ Andreou and Spanos (2003) argue that several estimated models by Nelson and Plosser (1982) could be misspecified, thus potentially biasing the performance of the unit root tests.
} 
autocorrelation, homoscedasticity, and linearity (Tables 3 and 4). The normality coefficients used are skewness, kurtosis, and Jarque-Bera. We employ the automatic Portmanteau (AQ) test for serial correlation (Escanciano and Lobato, 2009), the Lagrange Multiplier (LM) test for homoscedasticity (Engle, 1982) and the BDS test statistic for non-linearity (Brock, Dechert and Scheinkman, 1987).

Most of the original series indicate significant skewness and excess kurtosis implying that the assumption of Gaussian errors is not appropriate. As shown by Balke and Fomby (1994), outliers may cause significant skewness and excess kurtosis in macroeconomic time series. Indeed, these measures of non-normality decrease, sometimes quite dramatically, after correcting outliers. Evidence of excess skewness and excess kurtosis disappears for all the series, except for industrial production, GNP deflator, and nominal wages.

The AQ statistics are significant for all (outlier unadjusted and adjusted) series, except for real wages and velocity, implying the presence of serial linear correlation. Note that the serial linear correlation disappears for real GNP, industrial production and money stock when adjusting for outliers.

The data do not seem to contain conditional heteroscedasticity because the LM tests are not significant for most of the series. Further, interest rate, stock price, nominal GNP, and industrial production display a significant LM test when outliers are not removed from the data. Nevertheless, when these series are cleaned of outliers, the test becomes insignificant. This result confirms that of van Dijk et al. (2002), who report that if outliers are neglected, the LM test rejects the null hypothesis of conditional homoscedasticity too often when it is true. The exception is velocity, which seems to present conditional heteroscedasticity, even if outliers are removed from the data.

Finally, we apply the most widely used test for general non-linearity: the BDS test. Tables 3 and 4 indicate that all the uncorrected data, except real wages and stock prices, display non-linearity. However, in most cases the BDS test becomes insignificant when the outliers are removed. This result is consistent with that of Balke and Fomby (1994). Indeed, these authors showed that after fitting the outlier model and controlling for the effects of the outliers, the evidence of non-linearity in 15 post-World War II macroeconomic time series is substantially weaker. Nominal GNP, nominal wages, industrial production, and velocity show strong evidence of non-linearity even the effect of outliers is

Based on estimated models that are statistically adequate, they obtain different conclusions on the unit root hypothesis. 
controlled. ${ }^{12}$

\subsection{Infrequent Large Shocks}

In Tables 5-18, all detected outliers are given by series, together with their type, timing and t-statistics. In addition, we try to associate the date of each outlier to a specific event that occurred near that date. As expected, outliers are detected in all the series, giving strong proof of infrequent large shocks. Most of the shocks have a temporary effect but seven out of fourteen series experience a permanent shock. ${ }^{13}$ As suggested by Balke and Fomby (1994) and Darné and Diebolt (2004), most of the series experienced an infrequent large shock due to the Great Depression, World War II and recessions. ${ }^{14}$ Below, we examine the detected outliers that are linked with identifiable economic events for all the series. Given the clustering of outliers across series, i.e. an event can cause infrequent large shocks in different series, we describe the economic events that could affect the series chronologically. ${ }^{15}$

The expansion of 1862-1864 during the U.S. Civil War can explain the positive shocks experienced by consumer price. The negative shocks in 1893 and 1894 for employment, unemployment, GNP deflator, and money stock may have been caused by the recession of 1893-1894. In 1893, some railroad companies were placed in receivership, heralding the panic of 1893 . The negative shock in 1906 for unemployment can be explained by the expansion of 1905-1906 which was characterized by the growth of the productive system, in particular the construction of railroads. The negative shock detected in 1908 for industrial production, employment, unemployment (positive shock), nominal wages, real wages and money stock can be due to the short, but extremely severe, recession of 1907-1908 following the financial and banking panic of 1907.

The positive shocks in 1916 for GNP deflator and nominal wages; in 1917 for GNP deflator, consumer price and money stock; and in 1918 for real GNP, real per capita GNP, unemployment (negative shock), nominal wages, velocity, and

\footnotetext{
${ }^{12}$ The non-linearity displays by velocity can be explained by the presence of conditional heteroscedasticity.

${ }^{13}$ Using the $\operatorname{ARIMA}(0,1,0)$ model to improve the power of level shift detection, no level shifts are misidentified as innovative outliers.

${ }^{14}$ Blanchard and Simon (2001) argue that "recessions are largely the result of infrequent large shocks - indeed, sufficiently large and identifiable that they often have names: the first and second oil shocks, the Volcker disinflation, and so on".

${ }^{15}$ A detailed discussion of these economic events can be found in Charles and Darné (2009).
} 
interest rate may have been caused by World War I and the expansion of 19151918. This period was characterized by high inflation, which reflected massive gold imports from the European belligerent nations' buying war materials, as well as inflationary finance once the U.S. entered the war in 1917 (Bordo and Haubrich, 2004). The recession of 1920-1921 can explain the negative shocks identified in 1920 for unemployment (positive shock) and GNP deflator, and in 1921 for real GNP, real per capita GNP, nominal GNP, industrial production, employment, unemployment (positive shock), consumer price, nominal wages, and money stock. This recession can be caused by inflationary financing during World War I, which led the U.S. to apply a deflationary policy. The positive shock for nominal wages and the negative shock for unemployment in 1923 can be due to the rapid recovery that followed the recession.

The negative shock in 1928 for interest rates can be attributed to the tight monetary policy applied by the Federal Reserve to contain the developing stock market bubble, which was perceived as a threat to the continued progress and stability of the economy (Orphanides, 2003). This tight policy led to the stock market crash of October 1929 and the beginning of the Great Depression. All the series, except consumer price, real wages and velocity, experienced large negative shocks detected in 1930, 1931, and 1932 which may have been caused by the Great Depression during the 1930s in the U.S. The recession of 19371938, resulting from a decline in economic activity and the reduction of the public deficit, can explain the negative shocks in 1938 for real GNP, real per capita GNP, industrial production, employment, nominal wages, and real wages.

World War II had a strong positive impact on the period 1942-44 for unemployment (negative shock), nominal wages, and money stock due to the large rise in military spending as soon as the U.S. joined the war. During World War II, government expenditures were financed primarily by issuing debt. The U.S. economy was strongly affected in 1946 by the end of World War II owing to the readjustments in the economy after the wartime economy, which can explain the negative shock for real GNP, real per capita GNP, industrial production, employment, GNP deflator, and real wages.

The post-WWII infrequent large shocks are experienced only by interest rate, except employment and real per capita GDP in 1954. The 1954 negative shock can be explained by the short recession of 1953-1954, which was due to the readjustments in the expenditures after the end of the Korean War. The positive 
shock in 1957 can be attributed to the fear of inflation, which led the Fed to tighten monetary policy, and the negative shock in 1961 by less restrictive monetary policy led by the Fed. The positive shocks in 1968 and 1970 can be caused by expansionary monetary and fiscal policies to finance social programs and the Vietnam War. The positive shocks in 1980 and 1981 can be attributed to the Volcker aggressive disinflationary policy, intended to stabilize the inflation and the economy, which triggered by a severe recession. The positive shock in 1984 can be explained by the preemptive interest rate policy actions led by the Fed in 1983-84. Finally, the negative shock in 1986 may have been to an oil price decline, as well as the effect of the strong dollar.

\section{Intervention Models and Unit Root Tests}

Because the outliers can seriously affect the unit root tests (e.g., Franses and Haldrup, 1994; Lucas, 1995; Shin et al., 1996; Yin and Maddala, 1997; Cavaliere and Georgiev, 2009), we apply an ADF test corrected for detected outliers, as in Balke and Fomby (1991) and Bradley and Jansen (1995). ${ }^{16}$ This approach is equivalent to using the $\mathrm{ADF} t$-statistic for testing that $\rho=1$ in the following regression

$$
y_{t}=\mu+\beta t+\rho y_{t-1}+\sum_{j=1}^{m} f(t)_{i, j}+\sum_{i=0}^{k} \beta_{i} \Delta y_{t-i}+\varepsilon_{t}
$$

where $f(t)_{i, j}$ is defined as in equation (3), with $i=\mathrm{AO}, \mathrm{IO}, \mathrm{LS}$, TC, and $m$ being the number of outliers. ${ }^{17}$ A linear trend is introduced for all the series, except for unemployment. Given that model interventions are specific for each series we have generated critical values for the $t$-statistic from 10,000 replications, based on the number, type and dates of the outliers identified for each series. The $k$ lags that are estimated for each series are used to calculate critical values. As in Bradley and Jansen (1995), the tables include two sets of critical values for the unit root tests: (1) the B-F critical values generated by following the procedure used by Balke and Fomby (1991), for which the replications were performed on the specific intervention model for each country that was detected

\footnotetext{
${ }^{16}$ Rodriguez (2004) also uses this approach but only for additive outliers. Balke and Fomby (1991) and Bradley and Jansen (1995) do not take TCs into account.

${ }^{17}$ The null and alternative models include outliers, as suggested by Harvey et al. (2001) and Lee and Strazicich (2003).
} 
by the outlier analysis; and (2) the B-J critical values computed by following the approach employed by Bradley and Jansen (1995) for which the outlier analysis was applied at each replication and using these outliers to construct an intervention model. ${ }^{18}$

The results of the unit root test are displayed in Panel A of Tables 5-18. The lag order $k$ in the regression is selected using the sequential procedure proposed by Campbell and Perron (1991) and with $k_{\max }=$ int $\left[12 \times(T / 100)^{1 / 2}\right]$. The results show that the unit root null hypothesis can be rejected at the $5 \%$ level - using the B-F and B-J critical values - for 5 of the 14 macroeconomic time series of interest, namely real GNP, real per capita GNP, industrial production, employment and unemployment. This result is also obtained by recent studies using unit root tests with two structural breaks for some variables (see Table 19), e.g., Lumsdaine and Papell (1997) and Papell and Prodan (2007) for real GNP, real per capita GNP, and employment; Lumsdaine and Papell (1997) and Lee and Strazicich (2003) for industrial production; and Lumsdaine and Papell (1997), Lee and Strazicich (2003), and Papell and Prodan (2007) for unemployment. Therefore, our findings are slightly different from those of Nelson and Plosser (1982), especially with Lumsdaine and Papell (1997) on the nominal GNP. This difference can be explained by the presence of a third break, which is not taken into account by Lumsdaine and Papell (1997) because ignoring a second break in the one-break test can reduce the power of the test (Lee and Strazicich, 2003; Darné, 2009). It is thus logical to expect a similar loss of power from ignoring a third break in the two-break test. ${ }^{19}$ The difference between our results and those of Lee and Strazicich (2003) on five series can be explained by the presence of TCs and/or AOs in these series that are not taken into account by the Lee-Strazicich test, and could be biased in this test. Indeed, Franses and Haldrup (1994) and Yin and Maddala (1997) show that the unit

\footnotetext{
${ }^{18}$ Consistent with Bradley and Jansen (1995), the B-F and B-J critical values are very close. At times, the B-F critical values are actually higher in absolute value than the B-J critical values. We would like to thank the referee for suggesting the two approaches to generate the critical values.

${ }^{19} \mathrm{Kim}$ et al. (2000) show that the test of Zivot and Andrews (1992) may be biased when the dates of the structural change are not well chosen, and when a second break is present but not taken into account. Lumsdaine and Papell (1997) extended the Zivot and Andrews (1992) test to two structural changes; the previous criticism also applies to this test. Further, these two endogenous break unit root tests are invalid when there is a break under the null and spurious rejections can result (Nunes et al., 1997; Lee and Strazicich, 2001).
} 
root tests can be biased by the TCs. ${ }^{20}$

In addition, we show that real GNP, real per capita GNP, industrial production, employment and unemployment are affected by both low-frequency (due to major economic events) and high-frequency shocks (due to a stochastic trend).

We also compare our results with another approach based on robust methods for estimation and unit root testing developed by Cavaliere and Georgiev (2009). They propose a robust quasi maximum likelihood (QML) approach for the augmented Dickey-Fuller regression, giving the $\mathrm{ADF}^{Q M L}$ statistic test. They also propose a sequential procedure for the linear trend case by applying the robust QML approach on the GLS detrended series, as in Elliott and al. (1996) and $\mathrm{Ng}$ and Perron (2001). Panel B of Tables 5-18 gives the results of the robust QML approach and finds the rejection of the unit root hypothesis for employment, unemployment, industrial production, real GNP and real per capita GNP at the $5 \%$ level and money stock at the $10 \%$ level. These results confirm our findings from the ADF test corrected for detected outliers, except for money stock. Note that through robust unit root tests Lucas (1995a) also found that the null is rejected for real GNP, real per capita GNP, industrial production and unemployment but not for employment in the extended NelsonPlosser data (see Table 19). This difference can be explained by the fact that, as shown by Cavaliere and Georgiev (2009) in their Monte Carlo simulations, the robust QML approach is more powerful than the robust method proposed by Lucas $(1995 \mathrm{a}, 1995 \mathrm{~b}){ }^{21}$

\section{Conclusion}

This paper re-examined the nature of the trend in the Nelson-Plosser data set from an alternative method relative to the previous studies. We underlined the effects of large, but infrequent shocks due to major economic or financial events on U.S. macroeconomic time series, such as the Great Depression, World War II and recessions, using outlier methodology. We applied an ADF test corrected for detected outliers based on intervention models and found the

\footnotetext{
${ }^{20} \mathrm{~A}$ Monte Carlo experiment should study the effects of TCs on the unit root tests with structural breaks but this issue is beyond the scope of this paper.

${ }^{21}$ Cavaliere and Georgiev (2009) assert that their test is more powerful than the unit root test based on prior outlier identification, suggested by Perron and Rodriguez (2003b). Xiao and Lima (2005) analyze only real GNP and find evidence in favor of trend stationarity.
} 
rejection of the unit root null hypothesis for five of the fourteen Nelson-Plosser macroeconomic time series, namely real GNP, real per capita GNP, industrial production, employment and unemployment, suggesting that these variables are affected by both low and high-frequency shocks. Our findings are confirmed by those obtained from the robust QML approach suggested by Cavaliere and Georgiev (2009).

For the researchers seeking only a robust estimate for testing the unit root, the robust QML approach seems to be advisable. However, when identification of the dates of occurrence of the outliers is important, the procedure of applying an ADF test corrected for detected outliers based on intervention models is a recommanded. Future research should investigate these approaches in the cointegrating regression framework. 


\section{References}

[1] Andreou, E., Spanos, A., 2003. Statistical adequacy and the testing of trend versus difference stationarity and comments. Econometric Reviews $22,217-267$.

[2] Balke, N.S., 1993. Detecting level shifts in time series. Journal of Business and Economic Statistics 11, 81-92.

[3] Balke, N.S., Fomby, T.B., 1991. Shifting trends, segmented trends, and infrequent permanent shocks. Journal of Monetary Economics 28, 61-85.

[4] Balke, N.S., Fomby, T.B., 1994. Large shocks, small shocks, and economic fluctuations: Outliers in macroeconomic time series. Journal of Applied Econometrics 9, 181-200.

[5] Banerjee, A., Urga, G., 2005. Modelling structural breaks, long memory and stock market volatility: An overview. Journal of Econometrics 129, $1-34$.

[6] Blanchard, O., Simon, J., 2001. The long and large decline in U.S. output volatility. Brookings Papers on Economic Activity, 1:2001, 135-174.

[7] Bordo, M.D., Haubrich, J.G., 2004. The yield curve, recessions, and the credibility of the monetary regime: Long-run evidence, 1875-1997. Working Paper No 04-02, Federal Reserve Bank of Cleveland.

[8] Box, G.E.P., Tiao, G.C., 1975. Intervention analysis with applications to economic and environmental problems. Journal of the American Statistical Association 70, 70-79.

[9] Bradley, M.D., Jansen, D.W., 1995. Unit roots and infrequent large shocks: New international evidence on output growth. Journal of Money, Credit, and Banking 27, 876-893.

[10] Brock, W.A., Dechert, W.D., Scheinkman, J.A., 1987. A test for independence based on the correlation dimension. Econometric Reviews,, $15,197-235$.

[11] Campbell, J.Y., Clarida, R.H., 1987. The dollar and real interest rates. NBER Working Paper No 2151. 
[12] Campbell, J.Y., Perron, P., 1991. Pitfalls and opportunities: what macroeconomists should know about unit roots. In Blanchard O.J., Fisher S. (eds) NBER Macroeconomic Annual, Vol. 6, 141-201.

[13] Carlson, M., 2005. Causes of bank suspensions in the panic of 1893. Explorations in Economic History 42, 56-80.

[14] Cavaliere, G., Georgiev, I., 2009. Robust inference in autoregressions with multiple outliers. Econometric Theory, 25, 1625-1661.

[15] Chang, I., Tiao, G.C., Chen, C., 1988. Estimation of time series parameters in the presence of outliers. Technometrics 30, 193-204.

[16] Chen, C., Liu, L.M., 1993. Joint estimation of model parameters and outlier effects in time series. Journal of the American Statistical Association 88, 284-297.

[17] Chen, C., Tiao, G.C., 1990. Random level-shift time series model, ARIMA approximations, and level-shift detection. Journal of Business and Economic Statistics 8, 83-97.

[18] Charles, A., Darné, O., 2009. Large shocks in U.S. macroeconomic time series: 1860Ũ1988. LEMNA Working Paper No 200924, University of Nantes.

[19] Darné, O., 2009. Spurious rejections with endogenous break unit root tests in the presence of outliers and breaks. Communications in Statistics Ů Simulation and Computation 38, 1037-1050.

[20] Darné, O., Diebolt, C., 2004. Unit roots and infrequent large shocks: New international evidence on output. Journal of Monetary Economics 51, 14491465.

[21] DeJong, D.N., Nankervis, J.C., Savin, N.E., Whiteman, C.H., 1992. The power problems of unit root tests in time series with autoregressive errors. Journal of Econometrics 53, 323-343.

[22] DeJong, D.N., Whiteman, C.H., 1991. Reconsidering "Trends and random walks in macroeconomic time series". Journal of Monetary Economics 28, 221-254. 
[23] Durbin, J., Koopman, S.J., 2001. Time Series Analysis by State Space Methods. Oxford University Press, Oxford.

[24] Elliott, G., Rothenberg, T.J., Stock, J.H., 1996. Efficient tests for an autoregressive unit root. Econometrica 64, 813-836.

[25] Engle, R.F., 1982. Autoregressive conditional heteroscedasticity with estimates of the variance of United Kingdom inflations. Econometrica 50, 987-1007.

[26] Escanciano, J.C., Lobato, I.N., 2009. An automatic Portmanteau test for serial correlation. Journal of Econometrics 151, 140-149.

[27] Franses, P.H., Haldrup, N., 1994. The effects of additive outliers on tests for unit roots and cointegration. Journal of Business and Economic Statistics $12,471-478$.

[28] Friedman, M., Schwartz, A.J., 1963. A Monetary History of the United States, 1867-1960. Princeton University Press, Princeton.

[29] Gómez, V., Maravall, A., 1997. Programs TRAMO and SEATS: Instructions for the user (Beta version: June 1997). Working paper No 97001, Ministerio de Economía y Hacienda, Dirección General de Análisis y Programación Presupuestaria.

[30] Goodfriend, M., 2005. The monetary policy debate since October 1979: Lessons for theory and practice. Federal Reserve Bank of St. Louis Review (march/april 2005), 243-262.

[31] Haldrup, N., Sanó, A., 2008. A note on the Vogelsang test for additive outliers. Statistics and Probability Letters 78, 296-300.

[32] Harvey, D., Leybourne, S., Newbold, P., 2001. Innovational outlier unit root Ttests with an endogenously determined break in level. Oxford Bulletin of Economics and Statistics 63, 559-575.

[33] Hoek, H., Lucas A., van Dijk H.K., 1995. Classical and Bayesian aspects of robust unit root inference. Journal of Econometrics 69, 27-59.

[34] Hsu, C-C., Kuan, C-M., 2001. Distinguishing between trend-break models: Method and empirical evidence. Econometrics Journal 4, 171-190. 
[35] Kim, T-H., Leybourne, S.J., Newbold, P., 2000. Spurious rejections by Perron tests in the presence of a break. Oxford Bulletin of Economics and Statistics 62, 433-444.

[36] Lee J., Strazicich, M.C., 2001. Break point estimation and spurious rejections with endogenous unit root tests. Oxford Bulletin of Economics and Statistics 68, 535-558.

[37] Lee J., Strazicich, M.C., 2003. Minimum Lagrange multiplier unit root test with two structural break. The Review of Economics and Statistics 85, 1082-1089.

[38] Leybourne, S.J., Mills, T.C., Newbold, P., 1998. Spurious rejections by Dickey-Fuller tests in the presence of a break under the null, Journal of Econometrics 87, 191-203.

[39] Li, H., 1995. A re-examination of the Nelson-Plosser data set using recursive and sequential tests. Empirical Economics 20, 501-518.

[40] Lima, L.R., Filho, J., 2008. Further investigation of the uncertain trend in US GDP. Applied Economics 40, 1207-1216.

[41] Lucas, A., 1995a. An outlier robust unit root test with an application to the extended Nelson-Plosser data. Journal of Econometrics 66, 153-173.

[42] Lucas, A., 1995b. Unit root tests based on M estimators. Econometric Theory 11, 331-346.

[43] Lumsdaine, R.L., Papell, D.H., 1997. Multiple trend breaks and the unitroot hypothesis. Review of Economics and Statistics 79, 212-218.

[44] Maddala, G.S., Kim, I-M., 2000. Unit Roots, Cointegration and Structural Change. Cambridge University Press, Cambridge.

[45] Montañés, A., Reyes, M., 1998. Effect of a shift in the trend function on Dickey-Fuller unit root tests, Econometric Theory 14, 355-363.

[46] Montañés, A., Olloqui, I., Calvo, E., 2005. Selection of the break in the Perron-type tests. Journal of Econometrics 129, 41-64.

[47] Murray, C.J., Nelson, C.R., Zivot, E., 2003. Why are Beveridge-Nelson and unobserved component decomposition of GDP so different. Review of Economics and Statistics 85, 235-243. 
[48] Nelson, C.R., Plosser, C.I., 1982. Trends and random walks in macroeconomic time series. Journal of Monetary Economics 10, 139-162.

[49] NcNown, R., Puttitanun, T., 2002. New unit root tests of the NelsonPlosser data. Applied Economics Letters 9, 9-11.

[50] Ng, S., Perron, P., 2001. Lag length selection and the construction of unit root tests with good size and power. Econometrica 69, 1519-1554.

[51] Nunes, L., Newbold, P., Kuan, C., 1997. Testing for unit roots with breaks: Evidence on the great cCrash and the unit root hypothesis reconsidered. Oxford Bulletin of Economics and Statistics 59, 435-448.

[52] Odell, K.A., Weidenmier, M.D., 2004. Real shock, monetary aftershock: The 1906 San Francisco earthquake and the panic of 1907. Journal of Economic History 64, 1002-1027.

[53] Orphanides, A., 2003. Historical monetary policy analysis and the Taylor rule. Journal of Monetary Economics 50, 983-1022.

[54] Papell, D.H., Prodan, R., 2007. Restricted structural change and the unit root hypothesis. Economic Inquiry 45, 834-853.

[55] Perron, P., 1989. The great crash, the oil price shock, and the unit root hypothesis. Econometrica 57, 1361-1401.

[56] Perron, P., 1997. Further evidence on breaking trend functions in macroeconomic variables. Journal of Econometrics 80, 355-385.

[57] Perron, P., 2006. Dealing with Structural Breaks. In Mills, T.C., Patterson, K. (Eds.), New Palgrave Handbook of Econometrics, Vol. 1, MacMillan, London.

[58] Perron, P., Ng, S., 1996. Useful modifications to unit root tests with dependent errors and their local asymptotic properties. Review of Economic Studies 63, 435-465.

[59] Perron, P., Rodriguez, G., 2003a. GLS detrending, efficient unit root tests and structural change. Journal of Econometrics 115, 1-27.

[60] Perron, P., Rodriguez, G., 2003b. Searching for additive outliers in nonstationary time series. Journal of Time Series Analisis 24, 193Ü220. 
[61] Phillips, P.C.B., Perron, P., 1988. Testing for unit root in time series regression. Biometrika 75, 347-353.

[62] Poole, W., 1988. Monetary policy lessons of recent inflation and disinflation. Journal of Economic Perspectives 2, 73-100.

[63] Rodríguez , G., 2004. An empirical note about additive outliers and nonstationarity in Latin-American inflation series. Empirical Economics $29,361-372$

[64] Romer, C., Romer, D., 1989. Does monetary policy matter? A new test in the spirit of Friedman and Schwartz. NBER Working Paper No 2966.

[65] Rappoport, P., Reichlin, L., 1989. Segmented trends and non-stationary time series. The Economic Journal 99, 168-177.

[66] Rudebusch, G., 1992. Trends and random walk in macroeconomic time series: A re-examination. International Economic Review 33, 661-680.

[67] Rudebusch, G., 1993. The uncertain unit root in real GNP. American Economic Review 83, 264-272.

[68] Schotman, P., van Dijk, H.K., 1991. On Bayesian routes to unit roots. Journal of Applied Econometrics 6, 387-401.

[69] Sen, A., 2003. On unit-root tests when the alternative is a trend-break stationary process. Journal of Business and Economic Statistics 21, 174184.

[70] Sen, A., 2004. Are U.S. macroeconomic series difference stationary or trendbreak stationary? Applied Economics 36, 2025-2029.

[71] Sen, A., 2008. Behaviour of Dickey-Fuller tests when there is a break under the unit root null hypothesis. Statistics and Probability Letters 78, 622-628.

[72] Seo, B., 1999. Distribution theory for unit root tests with conditional heteroskedasticity. Journal of Econometric 91, 113-144.

[73] Shin, D.W., Sarkar, S., Lee, J.H., 1996. Unit root tests for time series with outliers. Statistics and Probability Letters 30, 189-197.

[74] Taylor, J.B., 1998. An historical analysis of monetary policy rules. NBER Working Paper No 6768. 
[75] Tolvi, J., 2001. Outliers in eleven finnish macroeconomic time series. Finnish Economic Papers 14, 14-32.

[76] Tsay, R.S., 1988. Outliers, level shifts, and variance changes in time series. Journal of Forecasting 7, 1-20.

[77] van Dijk, D., Franses, P.H., Lucas, A., 2002. Testing for ARCH in the presence of additive outliers. Journal of Applied Econometrics 14, 539-562.

[78] Vogelsang, T.J., 1997. Wald-type tests for detecting breaks in the trend function of a dynamic time series. Econometric Theory 13, 818-849.

[79] Vogelsang, T.J., 1999. Two simple procedures for testing for a unit root when there are additive outliers. Journal of Time Series Analysis 20, 237252.

[80] Xiao, Z., Lima, L.R., 2005. Testing unit root based on partially adaptive estimation. Working Paper No 1549, University of Illinois.

[81] Yin, Y., Maddala, G.S., 1997. The effects of different types of outliers on unit root tests. In Fomby and Hill (eds), Advances in Econometrics, Vol. 13, JAI Press, Greenwich, Conn.

[82] Zivot, E., Andrews, D.W.K., 1992. Further evidence on the great crash, the oil price shock and the unit root hypothesis. Journal of Business and Economic Statistics 10, 251-270. 
Table 1: Descriptive Statistics from ARIMA Models.

\begin{tabular}{|c|c|c|c|c|c|c|c|c|}
\hline Series & Sample & $\mathrm{T}$ & Model & Type & Skew & Kur & JB & $\mathrm{AQ}$ \\
\hline \multirow[t]{2}{*}{ Real GNP } & 1909-1988 & 80 & $(0,1,1)$ & o & -0.17 & 4.04 & 3.87 & $8.24^{*}$ \\
\hline & & & & c & 0.18 & 2.86 & 0.47 & 0.01 \\
\hline \multirow[t]{2}{*}{ Nominal GNP } & 1909-1988 & 80 & $(0,1,1)$ & o & $-0.99^{*}$ & $6.96^{*}$ & $63.72^{*}$ & $21.77^{*}$ \\
\hline & & & & $\mathrm{c}$ & 0.28 & 3.57 & 2.07 & $21.17^{*}$ \\
\hline \multirow[t]{2}{*}{ Real p.c. GNP } & $1909-1988$ & 80 & $(0,1,1)$ & o & -0.24 & 3.87 & 3.15 & $8.13^{*}$ \\
\hline & & & & c & 0.04 & 2.42 & 1.13 & $32.38^{*}$ \\
\hline \multirow[t]{2}{*}{ Industrial production } & $1860-1988$ & 129 & $(2,1,0)$ & o & $-0.76^{*}$ & $3.87^{*}$ & $16.39^{*}$ & $21.99^{*}$ \\
\hline & & & & c & $-0.46^{*}$ & 3.67 & $6.80^{*}$ & 2.91 \\
\hline \multirow[t]{2}{*}{ Employment } & $1890-1988$ & 99 & $(1,1,1)$ & o & $-0.49^{*}$ & $3.97^{*}$ & $7.69^{*}$ & $9.11^{*}$ \\
\hline & & & & c & -0.02 & 3.89 & 3.20 & $4.71^{*}$ \\
\hline \multirow[t]{2}{*}{ Unemployment } & $1890-1988$ & 99 & $(2,0,0)$ & o & -0.04 & $4.74^{*}$ & $12.44^{*}$ & $14.62^{*}$ \\
\hline & & & & c & 0.35 & 3.14 & 2.06 & $7.40^{*}$ \\
\hline \multirow[t]{2}{*}{ GNP deflator } & $1889-1988$ & 100 & $(0,1,1)$ & o & $-1.33^{*}$ & $11.87^{*}$ & $349.85^{*}$ & $27.54^{*}$ \\
\hline & & & & c & 0.17 & $4.45^{*}$ & $8.95^{*}$ & $62.02^{*}$ \\
\hline \multirow[t]{2}{*}{ Consumer Price } & $1860-1988$ & 129 & $(1,1,0)$ & o & $-1.32^{*}$ & $9.82^{*}$ & $282.88^{*}$ & $53.10^{*}$ \\
\hline & & & & c & -0.19 & 3.19 & 0.95 & $173.87^{*}$ \\
\hline
\end{tabular}

o: original series, c: corrected-outliers series. ${ }^{*}$ Significant at the $5 \%$ level. Skew, Kur and JB denote the normality coefficients, i.e. skewness, kurtosis and Jarque-Bera, respectively. AQ denotes the automatic Portmanteau test for serial correlation (Escanciano and Lobato, 2009). 
Table 2: Descriptive Statistics from ARIMA Models (continue).

\begin{tabular}{|c|c|c|c|c|c|c|c|c|}
\hline Series & Sample & $\mathrm{T}$ & Model & Type & Skew & Kur & JB & $\mathrm{AQ}$ \\
\hline \multirow[t]{2}{*}{ Nominal wages } & $1900-1988$ & 89 & $(0,1,2)$ & o & -0.46 & $5.75^{*}$ & $30.34^{*}$ & $17.91^{*}$ \\
\hline & & & & $\mathrm{c}$ & 0.04 & $4.17^{*}$ & 4.96 & $23.88^{*}$ \\
\hline \multirow[t]{2}{*}{ Real wages } & $1900-1988$ & 89 & $(1,1,0)$ & o & 0.05 & 3.18 & 0.15 & 2.32 \\
\hline & & & & c & -0.01 & 3.50 & 0.90 & 0.02 \\
\hline \multirow[t]{2}{*}{ Money stock } & $1889-1988$ & 100 & $(0,1,1)$ & o & -0.35 & $5.14^{*}$ & $20.70^{*}$ & $48.11^{*}$ \\
\hline & & & & $\mathrm{c}$ & 0.23 & 2.82 & 0.99 & 0.03 \\
\hline \multirow[t]{2}{*}{ Velocity } & $1869-1988$ & 120 & $(0,1,1)$ & o & $-0.47^{*}$ & 3.51 & $5.62^{*}$ & 2.62 \\
\hline & & & & $\mathrm{c}$ & -0.36 & 3.12 & 2.70 & 4.98 \\
\hline \multirow[t]{2}{*}{ Interest rate } & $1900-1988$ & 89 & $(2,1,0)$ & o & -0.41 & $6.40^{*}$ & $43.29^{*}$ & 1.43 \\
\hline & & & & $\mathrm{c}$ & 0.31 & 2.32 & 3.01 & $87.05^{*}$ \\
\hline \multirow[t]{2}{*}{ Stock price } & $1871-1988$ & 118 & $(0,1,1)$ & o & $-0.45^{*}$ & $4.29^{*}$ & $12.03^{*}$ & $3.95^{*}$ \\
\hline & & & & c & -0.04 & 2.46 & 1.43 & $3.45^{*}$ \\
\hline
\end{tabular}

o: original series, c: corrected-outliers series. ${ }^{*}$ Significant at the $5 \%$ level. Skew, Kur and JB denote the normality coefficients, i.e. skewness, kurtosis and Jarque-Bera, respectively. AQ denotes the automatic Portmanteau test for serial correlation (Escanciano and Lobato, 2009). 


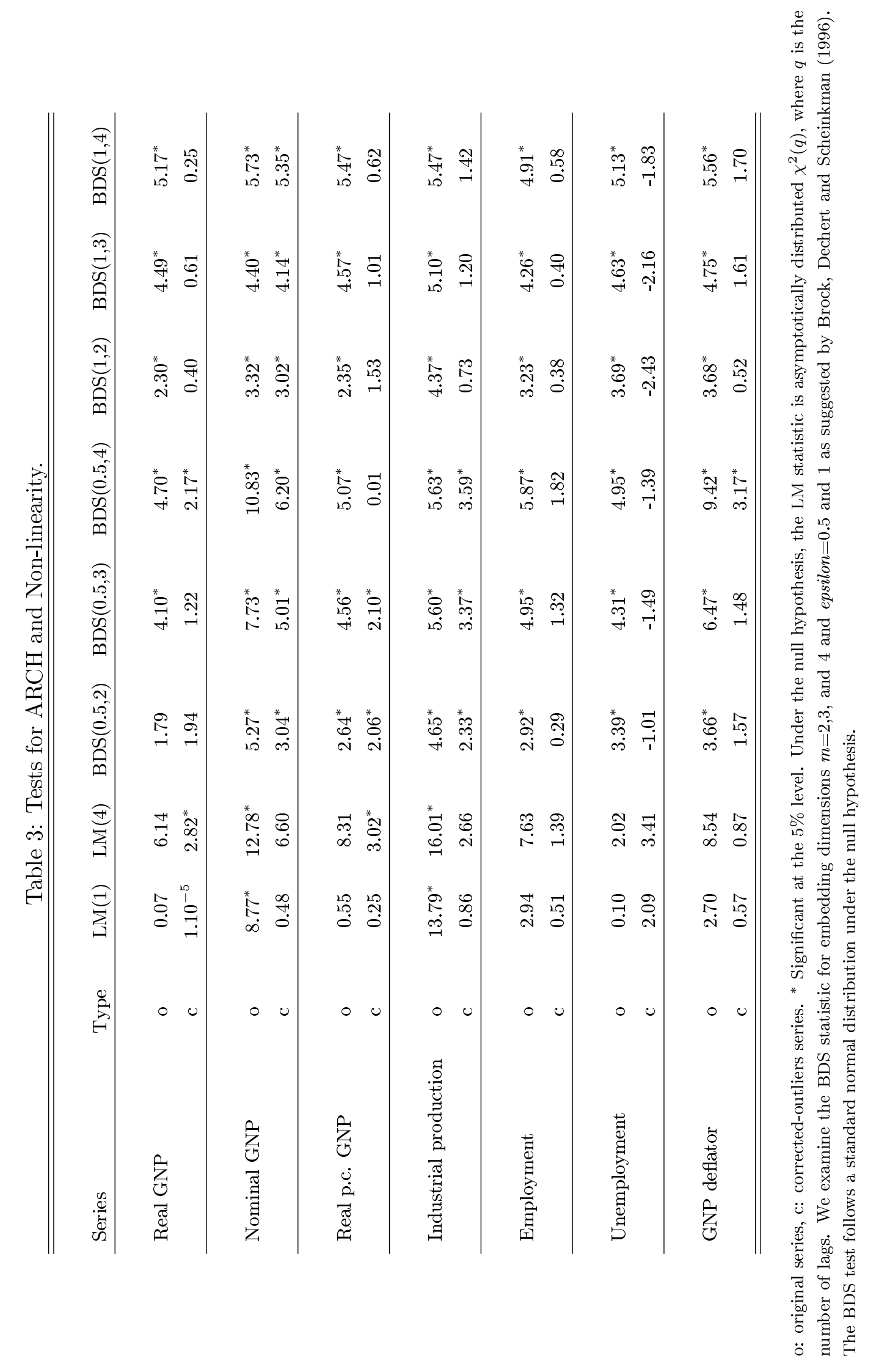




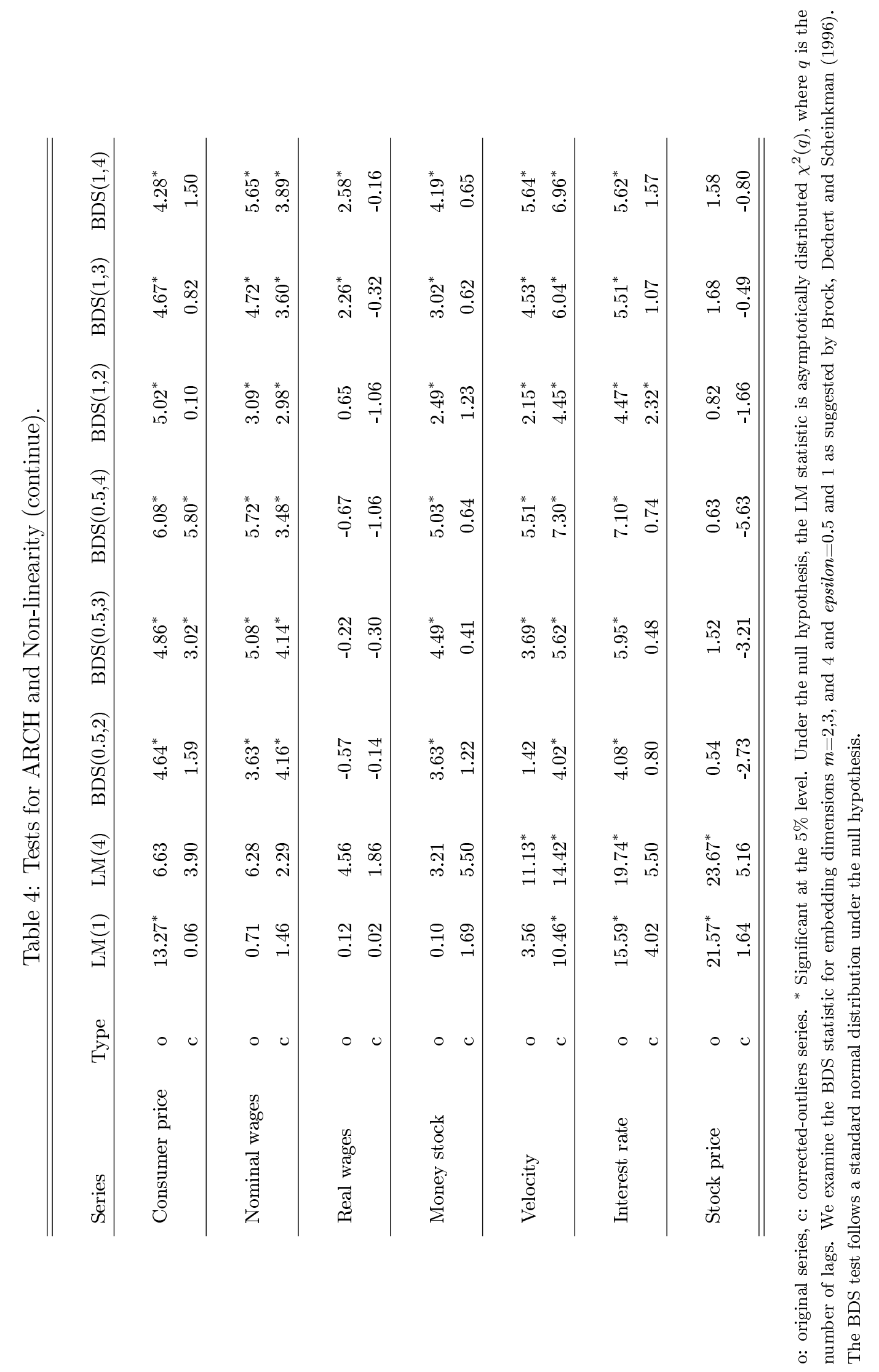


Table 5: Outliers detection for Real GNP.

\begin{tabular}{lccl}
\hline \hline Date & Type & t-stat & Events \\
\hline 1918 & TC & 4.32 & World War I, expansion \\
1921 & AO & -5.39 & Recession \\
1930 & IO & -4.50 & Great Depression \\
1932 & IO & -5.08 & Great Depression \\
1938 & TC & -3.79 & Recession \\
1946 & IO & -4.05 & End of World War II \\
\hline ADF $t$-stat & & -5.03 & \\
Critical value B-J 5\% & & -4.77 & \\
Critical value B-F $5 \%$ & & -4.99 & \\
\hline ADF ${ }^{Q M L} t$-stat & & -3.10 & \\
Critical value $5 \%$ & & -3.03 & \\
\hline \hline
\end{tabular}

Note: ADF $t$-stat denotes the ADF test statistic corrected for detected outliers based on the intervention model. $\mathrm{ADF}{ }^{Q M L}$ t-stat denotes the robust QML approach proposed by Cavaliere and Georgiev (2009).

Table 6: Outliers detection for Nominal GNP.

\begin{tabular}{lccl}
\hline \hline Date & Type & t-stat & Events \\
\hline 1921 & LS & -6.83 & Recession \\
1930 & IO & -3.64 & Great Depression \\
1931 & IO & -4.72 & Great Depression \\
\hline ADF $t$-stat & & -3.86 & \\
Critical value B-J 5\% & & -4.31 & \\
Critical value B-F 5\% & & -4.19 & \\
\hline ADF ${ }^{Q M L} t$-stat & & -2.78 & \\
Critical value 5\% & & -3.03 & \\
\hline \hline
\end{tabular}

Note: ADF $t$-stat denotes the ADF test statistic corrected for detected outliers based on the intervention model. $\mathrm{ADF}^{Q M L}$ t-stat denotes the robust QML approach proposed by Cavaliere and Georgiev (2009). 
Table 7: Outliers detection for Real per capita GNP.

\begin{tabular}{lccl}
\hline \hline Date & Type & t-stat & Events \\
\hline 1918 & TC & 5.67 & World War I, expansion \\
1921 & AO & -6.03 & Recession \\
1930 & IO & -4.82 & Great Depression \\
1932 & IO & -5.49 & Great Depression \\
1938 & TC & -4.34 & Recession \\
1946 & IO & -4.10 & End of World War II \\
1954 & AO & -3.71 & Recession \\
\hline ADF $t$-stat & & -5.27 & \\
Critical value B-J 5\% & & -5.08 & \\
Critical value B-F $5 \%$ & & -5.26 & \\
\hline ADF ${ }^{Q M L} t$-stat & & -3.07 & \\
Critical value $5 \%$ & & -3.03 & \\
\hline \hline
\end{tabular}

Note: ADF $t$-stat denotes the ADF test statistic corrected for detected outliers based on the intervention model. $\mathrm{ADF}^{Q M L}$ t-stat denotes the robust QML approach proposed by Cavaliere and Georgiev (2009).

Table 8: Outliers detection for Industrial production.

\begin{tabular}{lccl}
\hline \hline Date & Type & t-stat & Events \\
\hline 1908 & TC & -3.72 & Recession \\
1921 & AO & -5.55 & Recession \\
1930 & IO & -3.61 & Great Depression \\
1931 & IO & -3.36 & Great Depression \\
1932 & TC & -6.78 & Great Depression \\
1938 & TC & -6.03 & Recession \\
1946 & IO & -3.67 & End of World War II \\
\hline ADF $t$-stat & & -5.33 & \\
Critical value B-J 5\% & & -5.12 & \\
Critical value B-F 5\% & & -5.20 & \\
\hline ADF ${ }^{Q M L} t$-stat & & -3.22 & \\
Critical value $5 \%$ & & -3.03 & \\
\hline \hline
\end{tabular}

Note: ADF $t$-stat denotes the ADF test statistic corrected for detected outliers based on the intervention model. $\mathrm{ADF}^{Q M L}$ t-stat denotes the robust $\mathrm{QML}$ approach proposed by Cavaliere and Georgiev (2009). 
Table 9: Outliers detection for Employment.

\begin{tabular}{lccl}
\hline \hline Date & Type & t-stat & Events \\
\hline 1893 & IO & -4.85 & Recession \\
1894 & AO & -3.79 & Recession \\
1908 & AO & -3.55 & Recession \\
1921 & TC & -5.10 & Recession \\
1930 & IO & -3.63 & Great Depression \\
1931 & IO & -3.23 & Great Depression \\
1932 & IO & -4.86 & Great Depression \\
1938 & TC & -5.35 & Recession \\
1946 & IO & -5.18 & End of World War II \\
1954 & LS & -3.06 & Recession \\
\hline ADF $t$-stat & & -6.09 & \\
Critical value B-J $5 \%$ & & -5.89 & \\
Critical value B-F $5 \%$ & & -6.01 & \\
\hline ADF ${ }^{Q M L} t$-stat & & -3.28 & \\
Critical value $5 \%$ & -3.03 & \\
\hline \hline
\end{tabular}

Note: ADF $t$-stat denotes the ADF test statistic corrected for detected outliers based on the intervention model. $\mathrm{ADF} Q M L$-stat denotes the robust $\mathrm{QML}$ approach proposed by Cavaliere and Georgiev (2009). 
Table 10: Outliers detection for Unemployment.

\begin{tabular}{lccl}
\hline \hline Date & Type & t-stat & Events \\
\hline 1893 & TC & 6.04 & Recession \\
1894 & TC & 3.30 & Recession \\
1906 & IO & -4.01 & Expansion \\
1908 & AO & 3.94 & Recession \\
1918 & IO & -5.11 & World War I, expansion \\
1920 & IO & 3.63 & Recession \\
1921 & AO & 3.05 & Recession \\
1923 & AO & -5.18 & Expansion \\
1930 & IO & 3.99 & Great Depression \\
1931 & TC & 3.30 & Great Depression \\
1932 & LS & 6.36 & Great Depression \\
1942 & LS & -5.41 & World War II \\
1943 & IO & -4.32 & World War II \\
1944 & IO & -3.11 & World War II \\
\hline ADF $t$-stat & & -6.85 & \\
Critical value B-J $5 \%$ & & -6.19 & \\
Critical value B-F $5 \%$ & & -6.32 & \\
\hline ADF ${ }^{Q}$ t-stat & & -4.30 & \\
Critical value $5 \%$ & -3.03 & \\
\hline \hline
\end{tabular}

Note: ADF $t$-stat denotes the ADF test statistic corrected for detected outliers based on the intervention model. $\mathrm{ADF}^{Q M L} t$-stat denotes the robust QML approach proposed by Cavaliere and Georgiev (2009).

Table 11: Outliers detection for GNP deflator.

\begin{tabular}{lccl}
\hline \hline Date & Type & t-stat & Events \\
\hline 1893 & AO & 4.74 & Recession \\
1916 & IO & 3.27 & World War I, expansion \\
1917 & IO & 4.22 & World War I, expansion \\
1920 & AO & 12.32 & Recession \\
1931 & IO & -3.28 & Great Depression \\
1946 & IO & 3.01 & End of World War II \\
\hline ADF $t$-stat & & -2.98 & \\
Critical value B-J 5\% & & -4.84 & \\
Critical value B-F $5 \%$ & & -4.56 & \\
ADF ${ }^{Q M L} t$-stat & & -0.57 & \\
Critical value $5 \%$ & & -3.03 & \\
\hline \hline
\end{tabular}

Note: ADF $t$-stat denotes the ADF test statistic corrected for detected outliers based on the intervention model. $\mathrm{ADF}^{Q M L}$ t-stat denotes the robust $\mathrm{QML}$ approach proposed by Cavaliere and Georgiev (2009). 
Table 12: Outliers detection for Consumer price.

\begin{tabular}{lccl}
\hline \hline Date & Type & t-stat & Events \\
\hline 1862 & IO & 3.28 & Civil war, expansion \\
1863 & LS & 4.89 & Civil war, expansion \\
1864 & TC & 8.77 & Civil war, expansion \\
1917 & IO & 3.36 & World War I, expansion \\
1921 & IO & -7.36 & Recession \\
\hline ADF $t$-stat & & -3.38 & \\
Critical value B-J 5\% & & -4.93 & \\
Critical value B-F 5\% & & -5.25 & \\
\hline ADF ${ }^{Q M L} t$-stat & & -1.34 & \\
Critical value $5 \%$ & & -3.03 & \\
\hline \hline
\end{tabular}

Note: ADF $t$-stat denotes the ADF test statistic corrected for detected outliers based on the intervention model. $\mathrm{ADF}^{Q M L}$ t-stat denotes the robust QML approach proposed by Cavaliere and Georgiev (2009).

Table 13: Outliers detection for Nominal wages.

\begin{tabular}{lccl}
\hline \hline Date & Type & t-stat & Events \\
\hline 1908 & TC & -7.13 & Recession \\
1916 & IO & 4.99 & World War I, expansion \\
1918 & IO & 4.81 & World War I, expansion \\
1921 & IO & -7.50 & Recession \\
1923 & TC & 4.45 & Expansion \\
1932 & IO & -5.06 & Great Depression \\
1938 & TC & -5.52 & Recession \\
1941 & IO & 3.09 & World War II \\
\hline ADF $t$-stat & & -4.01 & \\
Critical value B-J $5 \%$ & & -5.59 & \\
Critical value B-F $5 \%$ & & -5.72 & \\
\hline ADF ${ }^{Q M L} t$-stat & & -2.17 & \\
Critical value 5\% & & -3.03 & \\
\hline \hline
\end{tabular}

Note: ADF $t$-stat denotes the ADF test statistic corrected for detected outliers based on the intervention model. $\mathrm{ADF}^{Q M L}$ t-stat denotes the robust QML approach proposed by Cavaliere and Georgiev (2009). 
Table 14: Outliers detection for Real wages.

\begin{tabular}{lccl}
\hline \hline Date & Type & t-stat & Events \\
\hline 1908 & AO & -3.70 & Recession \\
1915 & AO & -3.26 & Recession \\
1938 & TC & -3.29 & Recession \\
1946 & IO & -3.03 & End of World War II \\
\hline ADF $t$-stat & & -3.63 & \\
Critical value B-J 5\% & & -4.26 & \\
Critical value B-F 5\% & & -3.93 & \\
\hline ADF ${ }^{Q M L} t$-stat & & -1.83 & \\
Critical value $5 \%$ & & -3.03 & \\
\hline \hline
\end{tabular}

Note: ADF $t$-stat denotes the ADF test statistic corrected for detected outliers based on the intervention model. $\mathrm{ADF}{ }^{Q M L}$ t-stat denotes the robust QML approach proposed by Cavaliere and Georgiev (2009).

Table 15: Outliers detection for Money stock.

\begin{tabular}{lccl}
\hline \hline Date & Type & t-stat & Events \\
\hline 1893 & IO & -4.27 & Recession \\
1908 & AO & -4.45 & Recession \\
1917 & IO & 3.24 & World War I, expansion \\
1921 & IO & -4.22 & Recession \\
1931 & LS & -4.07 & Great Depression \\
1932 & IO & -7.01 & Great Depression \\
1943 & IO & 4.84 & World War II \\
1945 & TC & 3.41 & World War II \\
\hline ADF $t$-stat & & -2.41 & \\
Critical value B-J 5\% & & -5.65 & \\
Critical value B-F $5 \%$ & & -5.91 & \\
\hline ADF ${ }^{Q M L} t$-stat & & -2.95 & \\
Critical value $5 \%$ & & -3.03 & \\
\hline \hline
\end{tabular}

Note: ADF $t$-stat denotes the ADF test statistic corrected for detected outliers based on the intervention model. $\mathrm{ADF}{ }^{Q M L}$ t-stat denotes the robust QML approach proposed by Cavaliere and Georgiev (2009). 
Table 16: Outliers detection for Velocity.

\begin{tabular}{lccl}
\hline \hline Date & Type & t-stat & Events \\
\hline 1881 & LS & -3.34 & - \\
1918 & TC & 3.21 & World War I, expansion \\
\hline ADF $t$-stat & & -2.12 & \\
Critical value B-J 5\% & & -3.96 & \\
Critical value B-F 5\% & & -3.77 & \\
\hline ADF $^{Q M L}$ t-stat & & -0.95 & \\
Critical value 5\% & -3.03 & \\
\hline \hline
\end{tabular}

Note: ADF $t$-stat denotes the ADF test statistic corrected for detected outliers based on the intervention model. $\mathrm{ADF} Q M L$-stat denotes the robust $\mathrm{QML}$ approach proposed by Cavaliere and Georgiev (2009).

Table 17: Outliers detection for Interest rate.

\begin{tabular}{lccl}
\hline \hline Date & Type & t-stat & Events \\
\hline 1918 & TC & 6.04 & World War I, expansion \\
1928 & AO & -3.72 & Tight monetary policy \\
1932 & TC & 8.67 & Great Depression \\
1957 & AO & 5.83 & Tight monetary policy, recession \\
1961 & AO & -5.81 & restrictive monetary policy \\
1968 & IO & 5.42 & Expansionary monetary \\
1970 & AO & 15.32 & Expansionary monetary \\
1980 & IO & 9.93 & Volcker disinflation, recession \\
1981 & TC & 7.29 & Volcker disinflation, recession \\
1984 & AO & 19.98 & Inflation scare \\
1986 & LS & -21.36 & Fall in oil prices \\
\hline ADF $t$-stat & & -4.77 & \\
Critical value B-J 5\% & & -5.93 & \\
Critical value B-F $5 \%$ & & -6.08 & \\
\hline ADF ${ }^{Q M L} t$-stat & & -0.89 & \\
Critical value $5 \%$ & -3.03 & \\
\hline \hline
\end{tabular}

Note: ADF $t$-stat denotes the ADF test statistic corrected for detected outliers based on the intervention model. $\mathrm{ADF}^{Q M L} t$-stat denotes the robust $\mathrm{QML}$ approach proposed by Cavaliere and Georgiev (2009). 
Table 18: Outliers detection for Stock price.

\begin{tabular}{lccl}
\hline \hline Date & Type & t-stat & Events \\
\hline 1932 & TC & -5.19 & Great Depression \\
\hline ADF $t$-stat & & -2.26 & \\
Critical value B-J 5\% & & -3.53 & \\
Critical value B-F $5 \%$ & & -3.48 & \\
\hline ADF $^{Q M L}$ t-stat & & -2.19 & \\
Critical value 5\% & -3.03 & \\
\hline \hline
\end{tabular}

Note: ADF $t$-stat denotes the ADF test statistic corrected for detected outliers based on the intervention model. $\mathrm{ADF}^{Q M L}$ t-stat denotes the robust QML approach proposed by Cavaliere and Georgiev (2009).

Table 19: Unit roots in the Nelson-Plosser data set: Some recent studies.

\begin{tabular}{|c|c|c|c|c|c|c|c|c|}
\hline Data series & $\begin{array}{l}\text { Nelson } \\
\text { Plosser } \\
(1982)\end{array}$ & $\begin{array}{c}\text { Lumsdaine } \\
\text { Papell } \\
(1997)\end{array}$ & $\begin{array}{c}\text { Lee } \\
\text { Strazicich } \\
(2003)\end{array}$ & $\begin{array}{c}\text { Papell } \\
\text { Prodan } \\
(2007)\end{array}$ & $\begin{array}{l}\text { Lucas } \\
(1995)\end{array}$ & $\begin{array}{c}\text { Xiao } \\
\text { Lima } \\
(2005)\end{array}$ & $\begin{array}{c}\text { Intervention } \\
\text { model }\end{array}$ & $\begin{array}{c}\text { Robust } \\
\text { QML }\end{array}$ \\
\hline Real GNP & UR & NoUR & UR & NoUR & NoUR & NoUR & NoUR & NoUR \\
\hline Nominal GNP & UR & NoUR & UR & UR & UR & - & UR & UR \\
\hline Real p.c. GNP & UR & NoUR & UR & NoUR & NoUR & - & NoUR & NoUR \\
\hline Ind production & UR & NoUR & NoUR & UR & NoUR & - & NoUR & NoUR \\
\hline Employment & UR & NoUR & UR & NoUR & UR & - & NoUR & NoUR \\
\hline Unemployment & NoUR & NoUR & NoUR & NoUR & NoUR & - & NoUR & NoUR \\
\hline GNP deflator & UR & UR & UR & UR & UR & - & UR & UR \\
\hline Consumer prices & UR & UR & UR & UR & UR & - & UR & UR \\
\hline Nominal wages & UR & UR & UR & UR & UR & - & UR & UR \\
\hline Real wages & UR & UR & NoUR & UR & UR & - & UR & UR \\
\hline Money stock & UR & UR & NoUR & UR & UR & - & UR & UR \\
\hline Velocity & UR & UR & UR & UR & UR & - & UR & UR \\
\hline Interest rate & UR & UR & UR & UR & UR & - & UR & UR \\
\hline Stock price & UR & UR & UR & UR & UR & - & UR & UR \\
\hline
\end{tabular}

Note: Lumsdaine and Papell (1997), Lee and Strazicich (2003) and Papell and Prodan (2007) used unit root tests with two structural breaks from the original Nelson-Plosser data set whereas Lucas (1995) and Xiao and Lima (2005) employed robust unit root tests from the extended Nelson-Plosser data set. NoUR: No unit root; UR: unit root. 